Reusing the city, occupying urban skeletons, creating networks

\section{| RESUMEN |}

La reutilización de espacios desocupados y la participación comunitaria en tal proceso de activación, son las temáticas abordadas por el siguiente artículo, que nos aproximan a la obra realizada por Santiago Cirugeda y sus estrategias de asociatividad y trabajo colectivo.

\section{| ABSTRACT}

The reuse of vacant spaces and community involvement in this activation process, are the topics addressed by the next article, we approach the work done by Santiago Cirugeda and strategies of association and collective work.

\title{
Reusando la ciudad, ocupando esqueletos urbanos, creando redes
}

\section{RECICLAJE}

Numerosos edificios, públicos y privados, permanecen vacíos y sin uso alguno en el territorio español, especialmente en el interior de nuestras ciudades. Los usos que les daban sentido, ahora obsoletos, o procesos urbanos de muy diferentes problemáticas produjeron las causas de su abandono. Esta situación se ha visto acompañada por unas políticas tardías o inexistentes, que propusieran la incorporación de nuevos usos y el aprovechamiento instantáneo que estos edificios pueden generar.

El creciente interés que hay de diferentes proyectos europeos en la reutilización de estos elementos urbanos, por su idoneidad para incorporar usos temporales (como el programa Catalyst) o definitivos, nos obliga a sondear la capacidad funcional y simbólica de los miles de metros cuadrados de construcciones diversas que conviven con nosotros. La adaptación de los mismos abre las puertas a tipologías arquitectónica híbridas, y procesos económicos y sociales de muy fácil implementación, que en muchas ocasiones se convierten en revulsivos y activadores de la rehabilitación de los barrios donde están situados. Todo ello sin la necesidad de un mayor consumo territorial.
Igualmente diseminados por el territorio, tenemos centenares de ejemplos de edificaciones e infraestructuras que nunca se finalizaron, debido a estar cargadas por delitos urbanísticos, procesos especulativos o causas desconocidas. La localización de estos esqueletos urbanos, es primordial para evaluar el impacto ambiental de los mismos, y poder solicitar desde la ciudadanía autoorganizada medidas que devuelvan al territorio su estado original, ya que en muchas ocasiones nadie se quiere responsabilizar de la demolición de estos edificios o urbanizaciones fantasma.

Debemos conseguir montar un listado local de las edificaciones vacías y esqueletos urbanos, con el que posteriormente se elaboraría una guía donde se describan los edificios vacíos, con su emplazamiento, plantas y alzados, superficie construida, y los usos para los que estaban proyectados.

En el listado deberían contemplarse:

- Obras inacabadas por expedientes urbanísticos (esqueletos urbanos).

- Edificios equipamentales (públicos y privados) abandonados.

* Santiago Cirugeda P. es arquitecto ESARQ, Universitat Internacional de Catalunya. Sus intervenciones arquitectónicas se han vinculado con las intervenciones efímeras, el reciclaje y la participación ciudadana en la toma de decisiones. En tal dirección buena parte del trabajo de Cirujeda se realiza a partir del aprovechamiento de las restricciones normativas que rigen la ciudad, conocidas como recetas urbanas www.recetasurbanas.net. El trabajo de Cirujeda propicia la generación de trabajos colaborativos como la red Arquitectura colectivas, www.arquitecturascolectivas. ne 


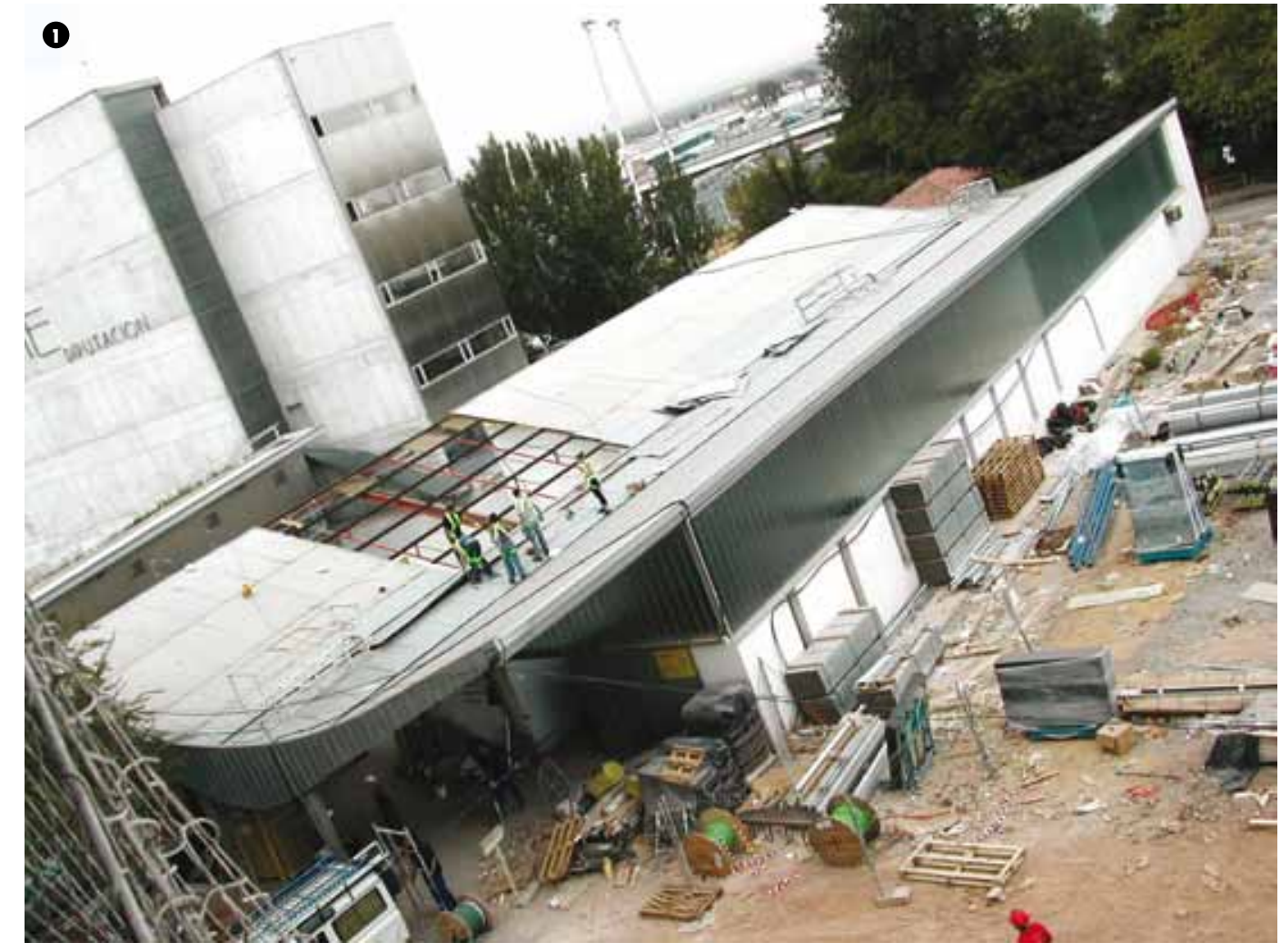

- Infraestructuras públicas en desuso o inacabadas.

- Vivienda vacía, en espera, en estado de ruina, etcétera.

Para articular todos los archivos e informaciones contradictorias o erróneas de la que hacen gala las administraciones, deberíamos poner de acuerdo un montón de entidades públicas responsables de este vacío informativo: Instituto Nacional de Estadística (y autonómicos), Ministerios de Fomento y Vivienda, Gerencias de Urbanismo, Registros de la propiedad, etcétera.

\section{OCUPACIÓN}

Lo que me ha producido estos 13 años de trabajo, casi en solitario, afectado y embebido de intereses y necesidades urbanas, de índole social, es plantear situaciones donde se reclama el derecho innato del ciudadano a usar la ciudad en la que vive. La pregunta: ¿̇Qué debe de hacer o aportar un grupo de ciudadanos para obtener el derecho de uso de un suelo o edificio obsoleto de propiedad pública? Un promotor ya sabemos...

Es entonces cuando aparece el concepto de ocupar. Últimamente escucho «ocupar» en todos los foros arquitectónicos y artísticos a los que asisto. Curiosamente, la mayor parte de personas que usan esa palabra como parte de la estrategia proyectual, sólo lo hacen por sus cualidades espaciales, y nunca como búsqueda de re-uso de elementos construidos, de poner en vida tejidos urbanos enfermos, quizás porque piensan que el terreno natural que rodea las ciudades es limitado.

Mientras intentamos animar $\mathrm{u}$ obligar a las administraciones al «cumplimiento debido», de los soportes legales, nosotros ocupamos y re-usamos estos elementos construidos de hormigón y acero. Organizados como grupos o colectivos, ocupamos calles, plazas, fachadas, azoteas, cubiertas, árboles, edificios y solares con una serie de «pollos» diversos, como a mí me gusta llamarlos.

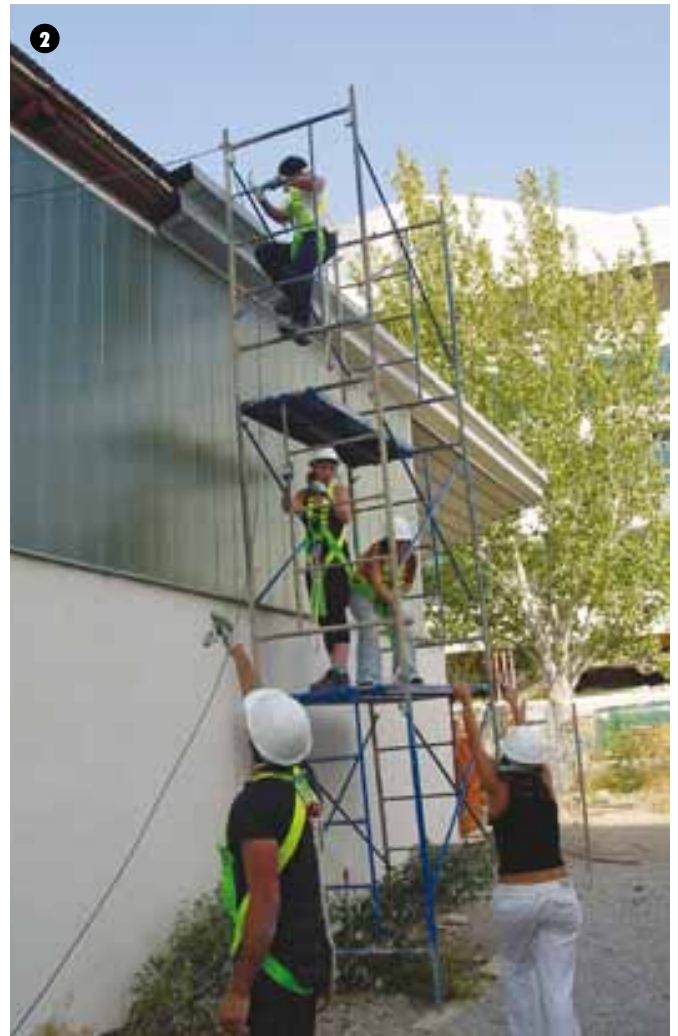

Paralelamente, recordemos que España está a la cola de los países europeos en el reuso y reciclaje de residuos y materiales de construcción, a pesar de la importancia y fomento del sector en los últimos quince años.

La experiencia de Aula Abierta, que hicimos en Granada (www.recetasurbanas.net), marca una vía para demostrar que incluso la arquitectura que fue diseñada para ser estática puede comportarse de una manera dinámica y transformarse en otro edificio totalmente flexible. Una manera de transformar un bien inmueble de propiedad pública obsoleto y a punto de demolerse, con la creación de los residuos pertinentes, en otro bien (in)mueble cuya gestión y aportaciones ciudadanas lo convierten en un equipamiento público autogestionado que se sale de un planeamiento urbano codificado, fruto de una actitud de gente que replantea las situaciones que les rodean. 

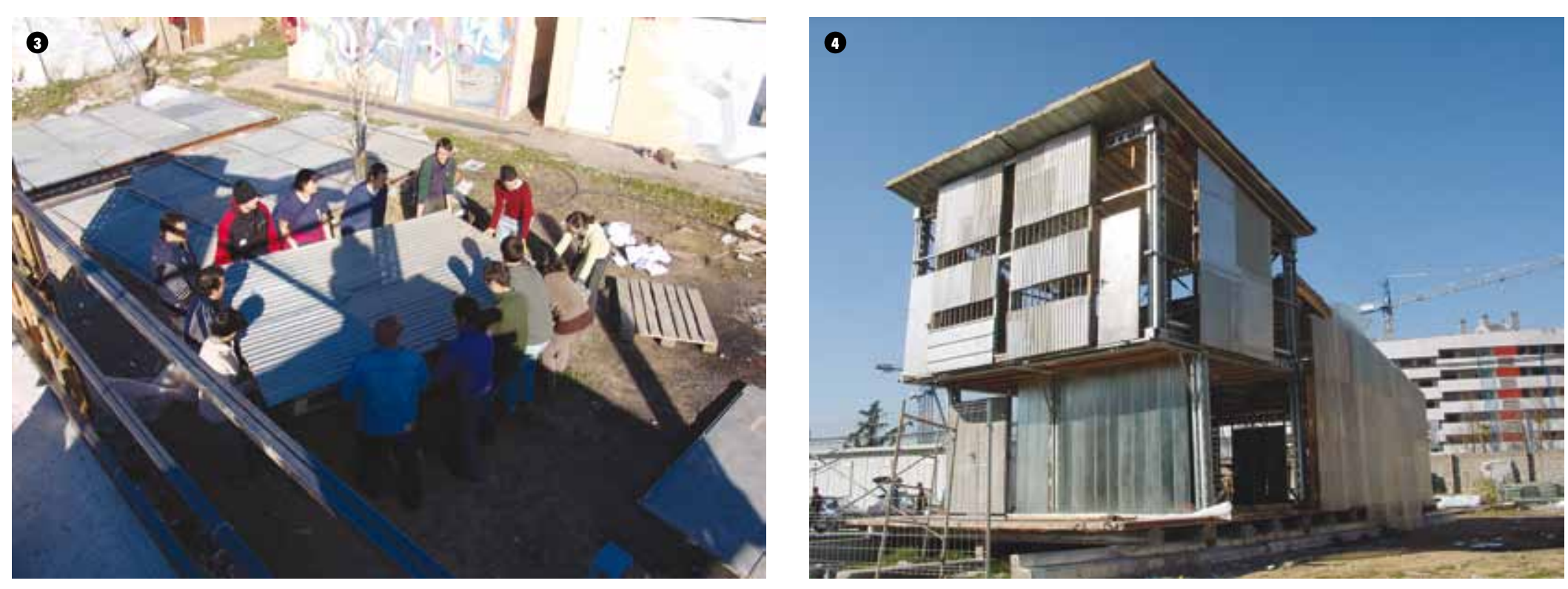

5

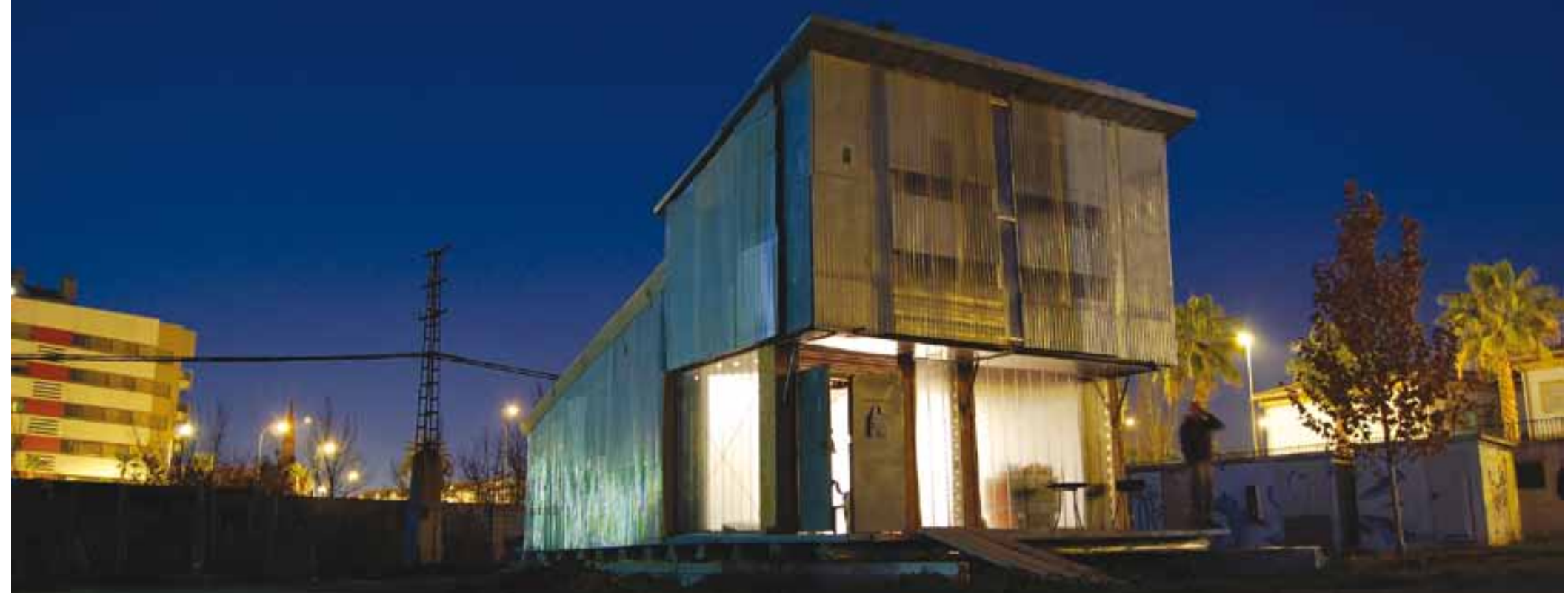




\section{- CAMIONES, CONTENEDORES \& COLECTIVOS}

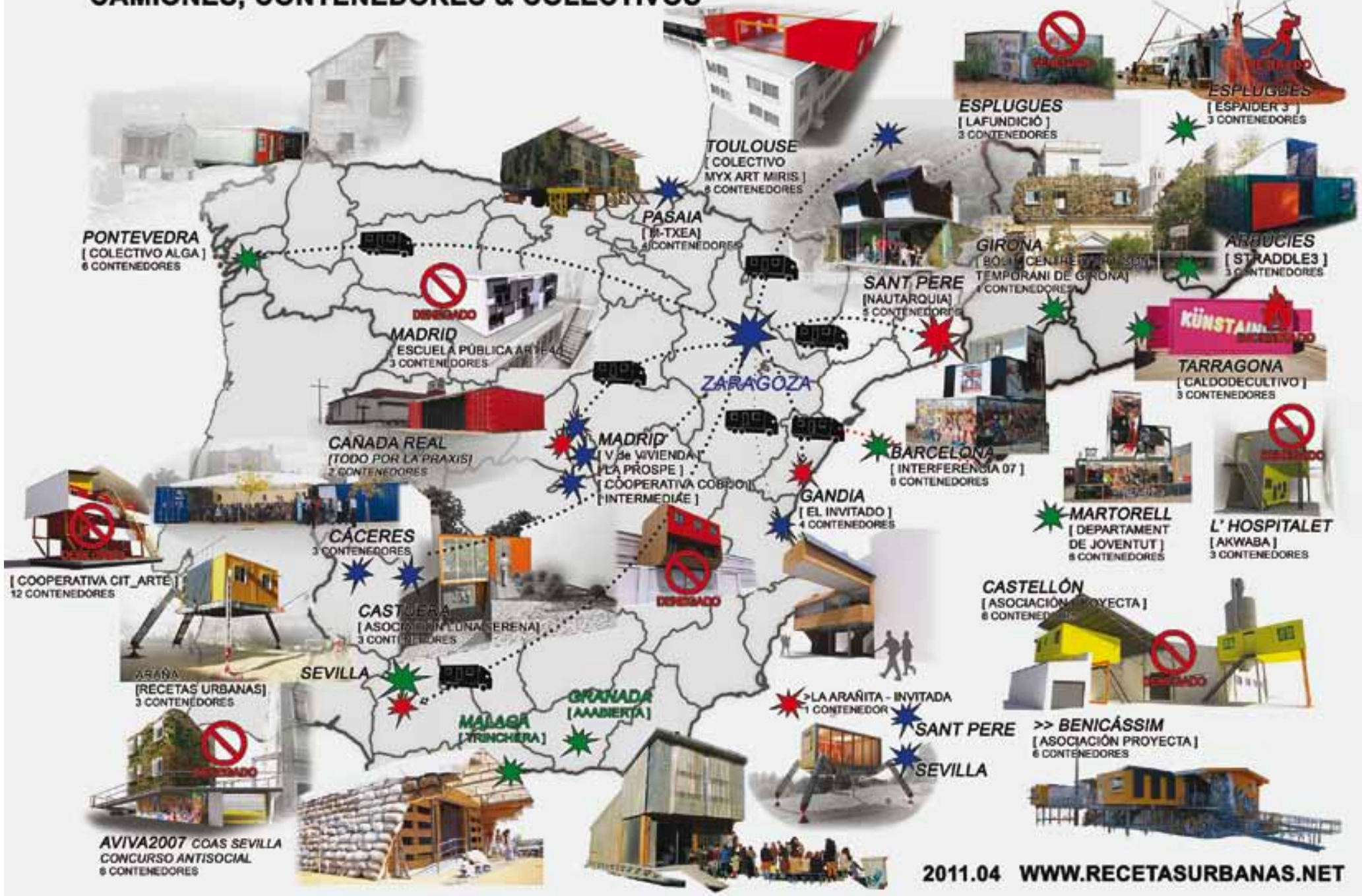

\section{ARQUITECTURAS COLECTIVAS}

Otra propuesta de recuperación y re-uso de patrimonio mobiliario es la demanda de visibilizar los almacenes de materiales y residuos públicos que pudieran ser usados por diferentes grupos para la construcción de equipamientos o viviendas.

Casualmente, tras una conferencia impartida en el COA (Colegio Oficial de Arquitectos) de Zaragoza, Juan Rubio del Val, de la Sociedad Municipal de Rehabilitación Urbana de Zaragoza, me explicó que les "sobraban» 14 viviendas de $42 \mathrm{~m}^{2}$ prefabricadas a partir de tres módulos. Las casas habían servido como alojamiento temporal para un grupo de familias de etnia gitana que residieron en ellas durante dos años, mientras esperaban poder acceder a pisos de protección oficial. Una vez realojados, el Ayuntamiento no podía quedarse con los módulos, y de una manera excepcional las cedió a quien las quisiera, siempre que dejáramos el solar en el que estaban en un máximo de tres meses.

A partir del 1 de marzo de 2007, el equipo de Recetas Urbanas procedió a ofrecer a las asambleas, colectivos, cooperativas y asociaciones la posibilidad de adjudicarles gratuitamente diferentes contenedores como sede residencial y/o de trabajo. El 4 de mayo se recogió de Zaragoza el último contendor con destino a Sevilla: en tres meses las viviendas se habían distribuido por la península, algunas almacenadas con carácter provisional, y otras ya instaladas en su lugar definitivo. El gasto de transporte, instalación y gestión de licencias correría a cargo de los grupos que asumieran la responsabilidad de darle uso. Recetas Urbanas colabora con los colectivos que lo pidan, en el acondicionamiento y tuneado de los mismos, así como realiza las justificaciones técnicas, el proyecto de instalación y los documentos necesarios para su legalización. 

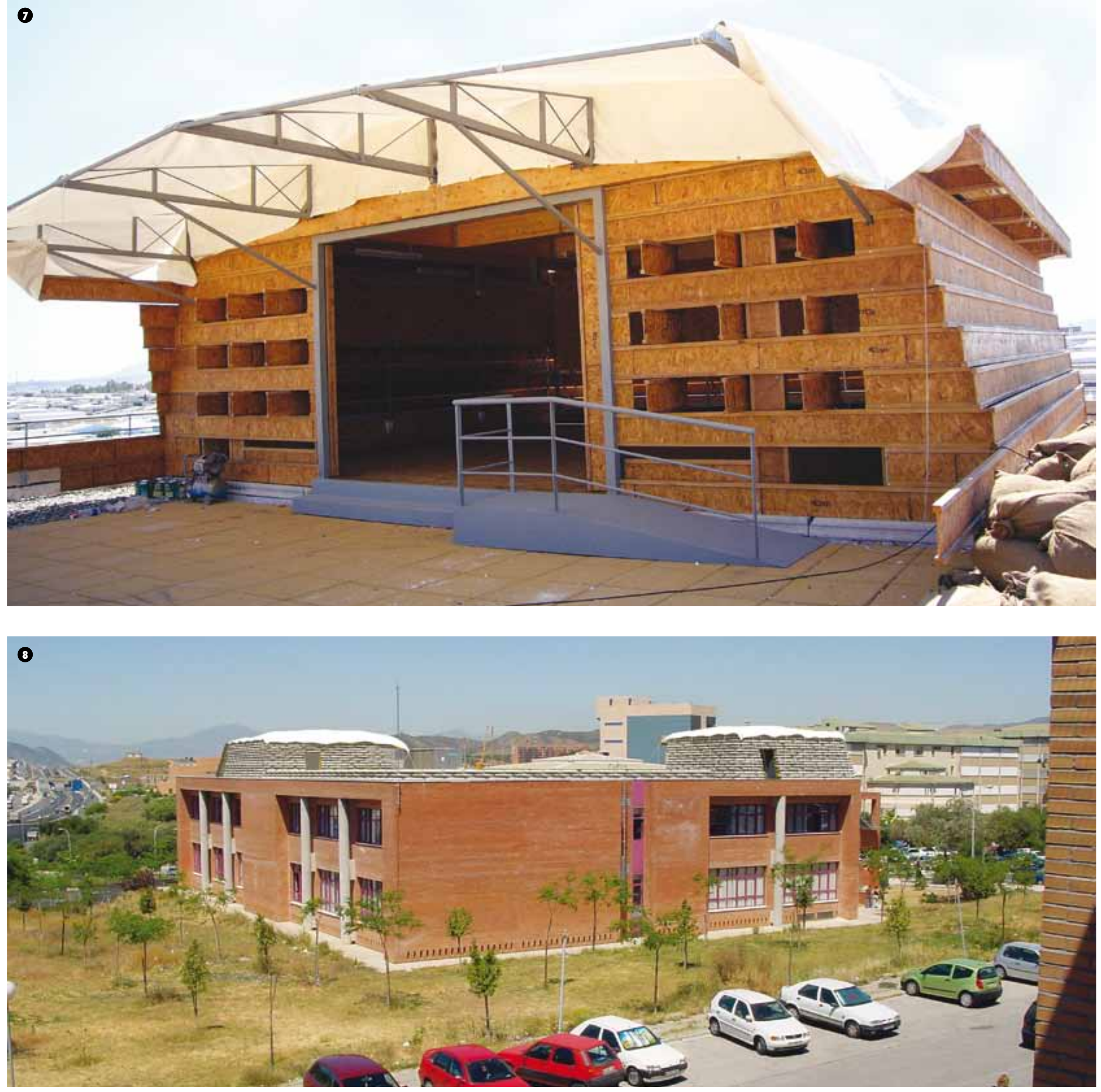

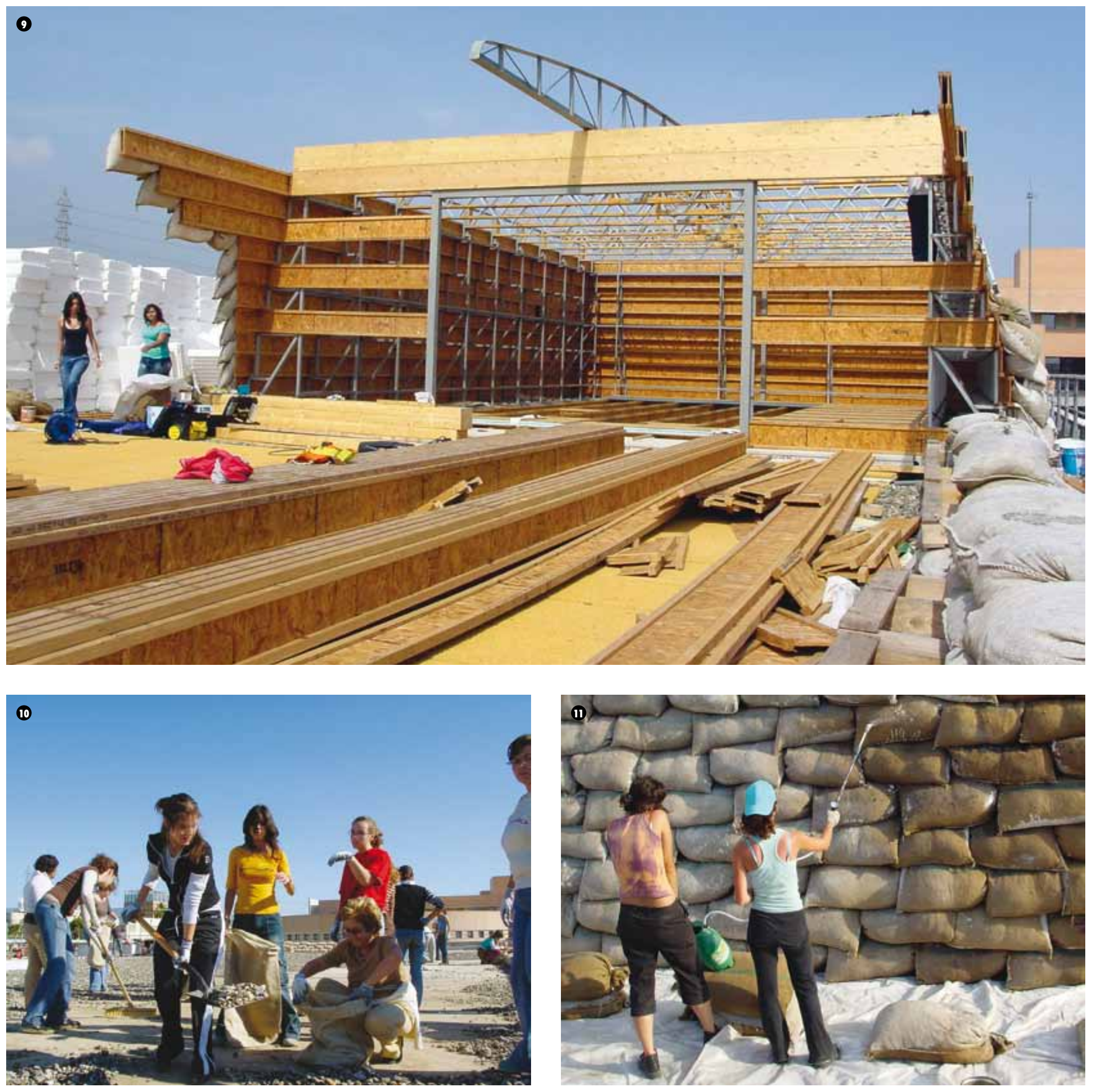
12. Proyectalab, Recetas Urbanas, Asociación Proyecta y varios colectivos, Benicassim, España, 2011.

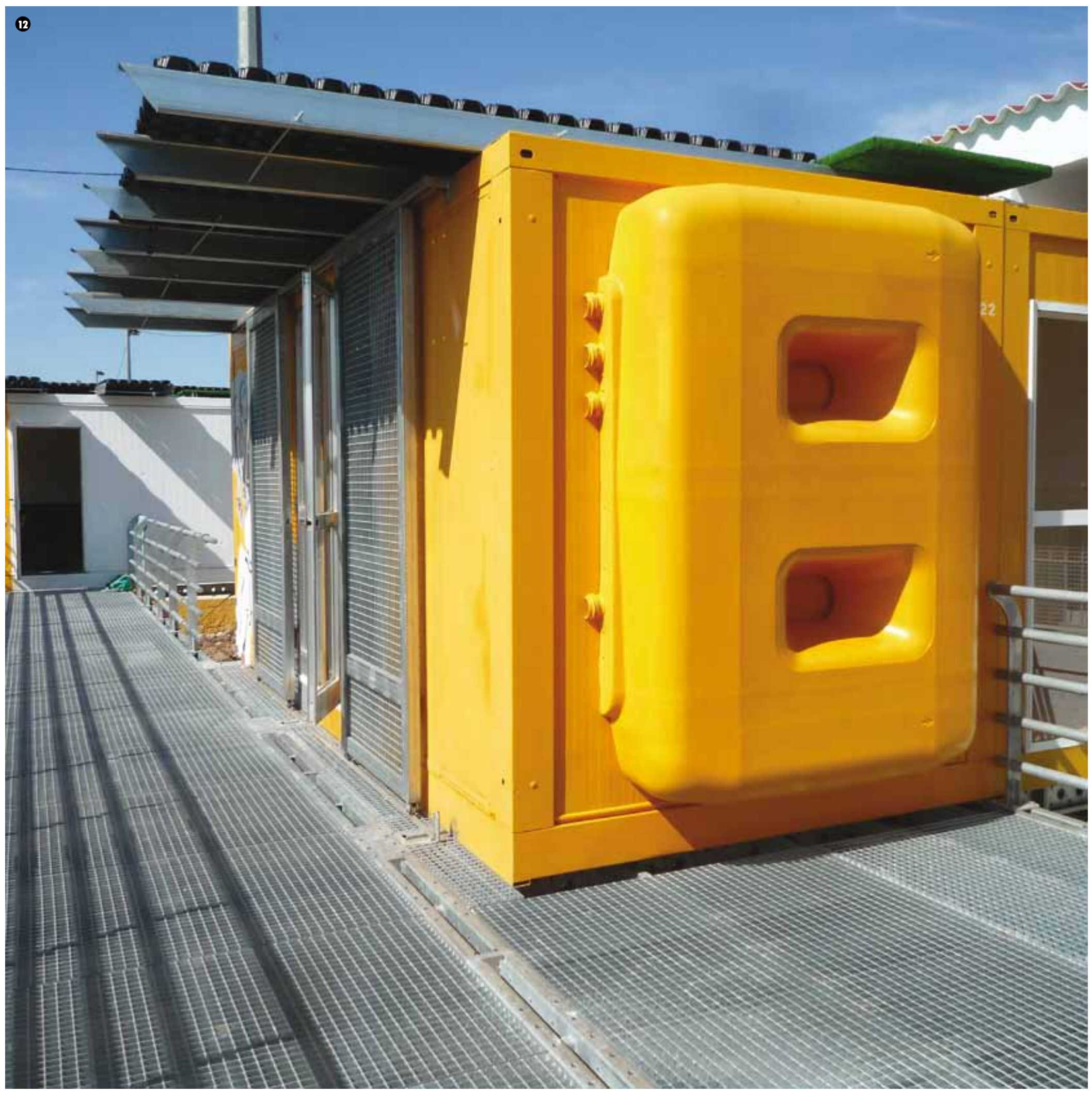


Los colectivos también cuentan con el apoyo de Recetas Urbanas para tener el seguro de responsabilidad civil del arquitecto, siempre que optasen por legalizarlo.

\section{Este grupo de proyectos sirven como} experimentos de distintas situaciones colectivas, que con los meses nos han enseñado como configurar distintos protocolos de gestión, financiación, mecanismos de ocupación de solares y edificios y la manera de trabajar internamente, como colectivo, cooperativa o asociación.

Cada colectivo está desarrollando su propio proyecto con estos módulos. La Fundició (www. lafundició.net), un colectivo vinculado a la educación alternativa, construyó la asociación EspaiDer3, con su propio espacio físico, un lugar de reunión y estudio para adolescentes. Pese a llevar tiempo trabajando en Esplugues del Llobregat, vieron como su módulo era retirado por la policía municipal, acabándose la experiencia de autogestión y autoconstrucción con los adolescentes. Bòlit, el nuevo centro de arte contemporáneo de Girona, ha instalado en su sede temporal una prótesis con cuatro módulos llamada El Niu. Pese a la idoneidad del proyecto cultural-ampliar los usos de un centro de este tipo, plantear qué necesidades puede tener el nuevo edificio- ha sido atacado duramente por distintos medios de comunicación locales, con el fin de desprestigiar al consistorio actual.

Todos los proyectos, ya sean en un ámbito rural (ParkAPart, Nautarquía, Alga-Lab) como en uno urbano (Proyectalab, Kunstaïner, Un lugar de Creación) se pondrán en común durante una reunión en el verano de 2009, como continuación de la reunión realizada en Córdoba en septiembre de 2007. Cada uno de estos proyectos ha estado mejor o peor coordinados; han sido acompañados por la administración o denegados y atacados; y han durado más o menos en tiempo. Lo que se plantea en estas reuniones periódicas es compartir el trabajo y experiencia de todos los colectivos, resolver las dudas que se plantearon en Córdoba, y poner en común los problemas de gestión, las posiciones políticas, la financiación, etc. Este trabajo colectivo posibilita tener un amplio muestrario de opciones de trabajo colectivo, que puede servir de punto de partida a grupos de ciudadanos que quieran participar activamente en la creación de su entorno cultural y social.

El reciclaje de los contenedores ha involucrado hasta la fecha a un número de 25 colectivos que trabajan con la autoconstrucción como una de sus armas de participación, el sondeo y contactos realizados en los últimos 3 años de trabajo intenso no se ha limitado a ellos, produciéndose numerosas colaboraciones. El éxito y la expansión vírica de la propuesta inicial demuestra lo importante que son los procesos de autogestión que complementan o proponen un trabajo social y político diferente al del poder que trata incisivamente de controlar cualquier actividad ciudadana. La capacidad de afectación ha variado desde el comienzo de la preparación o autoconstrucción, hasta conseguir la permanencia de meses incluso años. Seguimos aprendiendo y evaluando la eficacia, igual que lo hacemos con los políticos.

\section{LA DESIDIA POLÍTICA (PARTIDISTA)}

Reciclaje de antigua nave de Trenes. Proyectalab Benicassim 2011

Proyectalab es un espacio multidisciplinar que está destinado a albergar diferentes actividades culturales como cursos, workshops, exposiciones, jornadas, encuentros, etc. y que nace con la voluntad de convertirse en una sede disponible para aquellas personas o colectivos que no disponen de los recursos necesarios.

Iniciado por la Asociación Proyecta y construido por Recetas Urbanas en colaboración con Rehasa Estructuras, Lucas Construcción y la ayuda de numerosos colectivos, este espacio promovido por el Ayuntamiento de Benicàssim parte de la reutilización de 6 módulos vivienda procedentes de Zaragoza y pertenecientes al proyecto Camiones, Contendores \& Colectivos.

La obra ha supuesto la rehabilitación y mejora de un antiguo almacén de Renfe al cual se han adherido los contenedores en una prótesis que le capacita para nuevos usos. Con este proceso de construcción colectiva participativa y de reciclaje de espacios y materiales se ha obtenido una nueva instalación de forma enormemente rápida y económica.

Equipado con diferentes aulas, talleres, salas de reuniones, residencias de artistas y almacenes, este espacio de casi $400 \mathrm{~m}^{2}$ tenía que albergar mediante un modelo de gestión compartida las actividades de la «Nau de les Arts» durante el invierno y las del Proyectalab en verano, haciendo posible el aprovechamiento para múltiples usos de una misma infraestructura.

La construcción, desarrollada en 7 meses, ha sido hecha en colaboración con diferentes equipos de todo el país, los New Now, Straddle3, Todo por la Praxis, el Barranco, Conceptuarte, Asociación Proyecta, Recetas Urbanas y un montón de amigos que han venido a poner tornillos.

Tras la inauguración y sufriendo un cambio de partido en las elecciones municipales, el edificio lleva, a noviembre de 2011 , siete meses cerrado y sin ninguna actividad, incluso con amenazas por el nuevo partido de gobierno en contra de la anterior política local. Se repite la política torpe de los partidos, que al sucederse tienden a destrozar lo que los anteriores apoyaron.

De todos los proyectos realizados con los módulos, es el primero en el que intentando negociar de buena fe con las administraciones, y no habiendo firmado un convenio de cesión, nos encontramos con la soberbia y estupidez de unos políticos tan alejados de la realidad sociocultural actual, que termina por imponerse con unos criterios temerosos y autoritarios.

Actualmente se plantean estrategias desde la acción social y el entretenimiento legal.

\section{NUESTRA AUTOEVALUCIÓN}

Incluimos este cuestionario para que cualquier lector que pertenezca a un grupo, asamblea, colectivo, asociación, etc. que quiera incorporar sus ideas a este proyecto pueda mandar sus respuestasasc@recetasurbanas.net, desde donde se darán a conocer a todos los usuarios de esta red de colectivos, y donde se intentará evaluar nuestras propias estrategias. 
13. Proyectalab, Recetas Urbanas, Asociación Proyecta y varios colectivos, Benicassim, España, 2011.

\section{PROTOCOLOS DE TRABAJO E IDENTIDAD} COLECTIVA. PREGUNTAS:

- Nombre del Colectivo. Tipo de agrupación. Número y tipo de Miembros.

- Formación / profesionalización. Aportaciones o necesidades profesionales.

- Temporalidad / Antigüedad / Etapas.

- Objetivos Fundamentales. Áreas de trabajo.

- Visión/compromiso político. Financiación (real y necesaria). Legalidad.

- Relaciones Institucionales e Intercolectivas. Procedimientos de interlocución.

- Formatos de reunión y toma de decisiones. Jerarquías.

- Espacio físico y digital de trabajo.

- Repercusión pública. Manifestaciones. Mass Media.

- Cumplimiento de objetivos. La realidad. Éxitos y fracasos.

- Historias, anécdotas, evaluaciones personales.

- $\quad \dot{2}$ Creéis que una red bien articulada de colectivos y asociaciones puede generar un tercer poder? ¿̇una sociedad civil bien organizada, detrás del poder económico y el poder político? ¿Cuáles son sus armas?

\section{LINKS}

www.recetasurbanas.net www.colectivosenlared.org www.arquitecturascolectivas.net www.meipi.org/redaacc.meipi.php

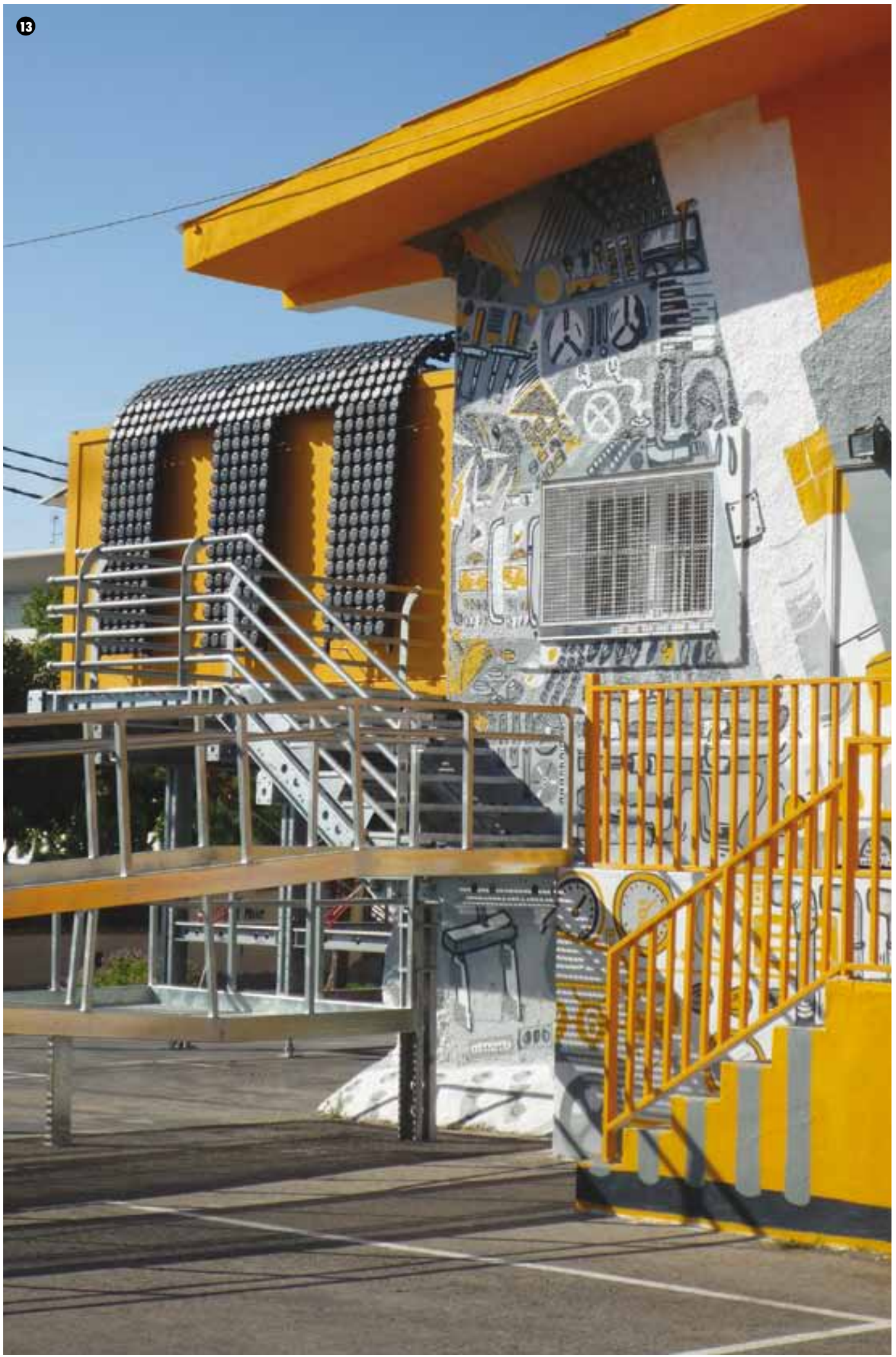



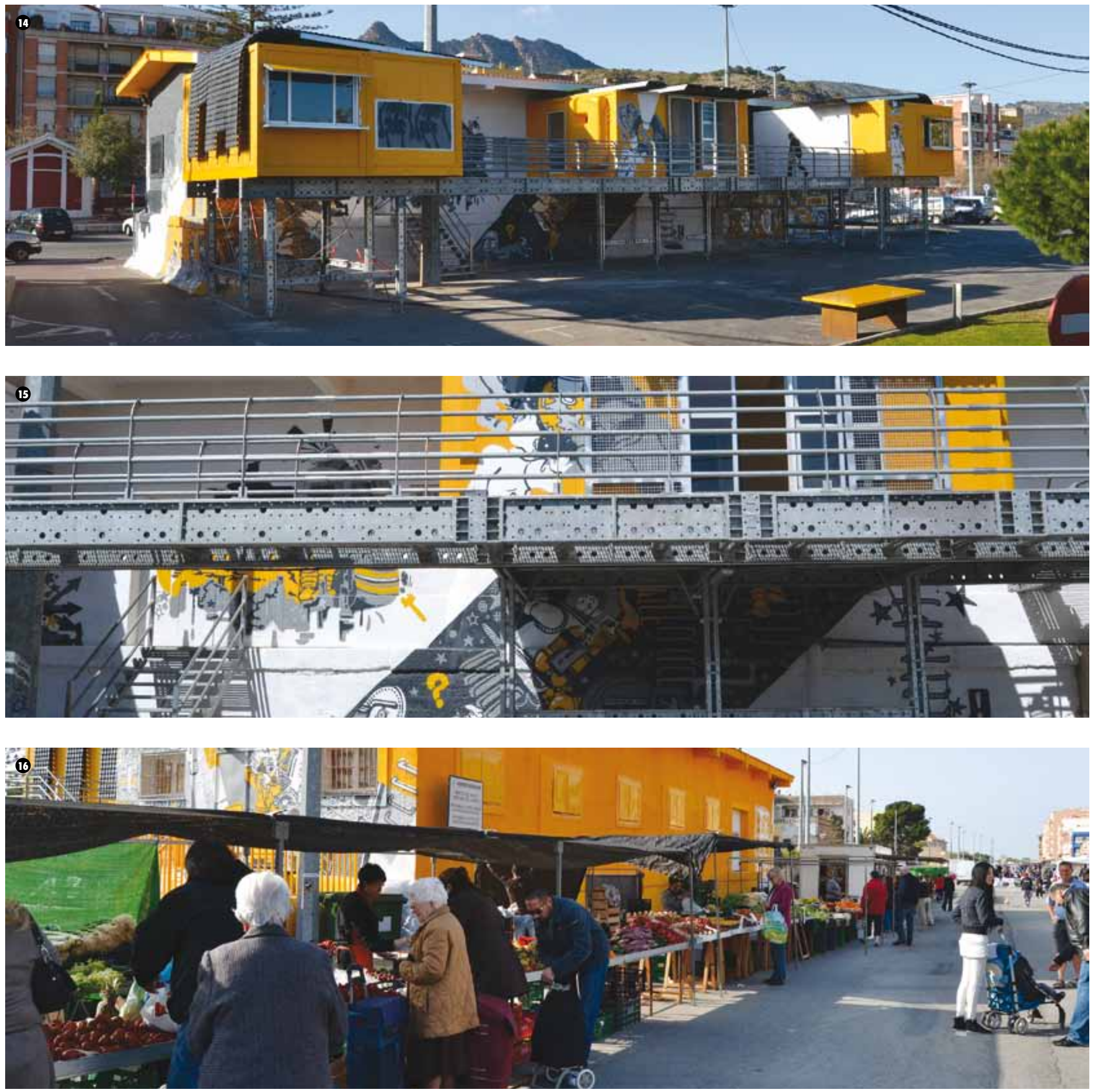
17. Proyecto Barranco, Colectivo Los Avatares asociado con varios colectivos, Pradejón, España, 2011

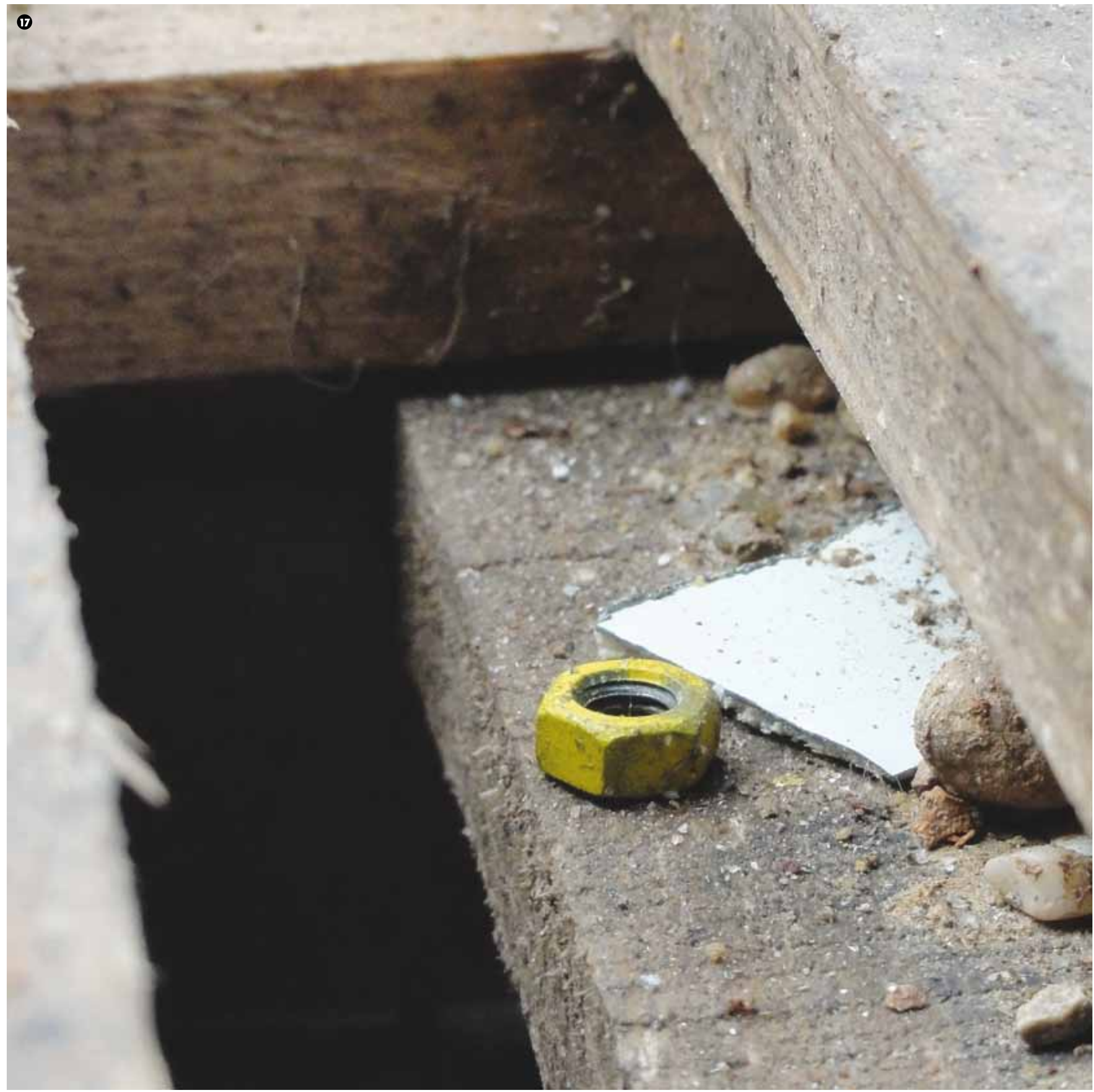



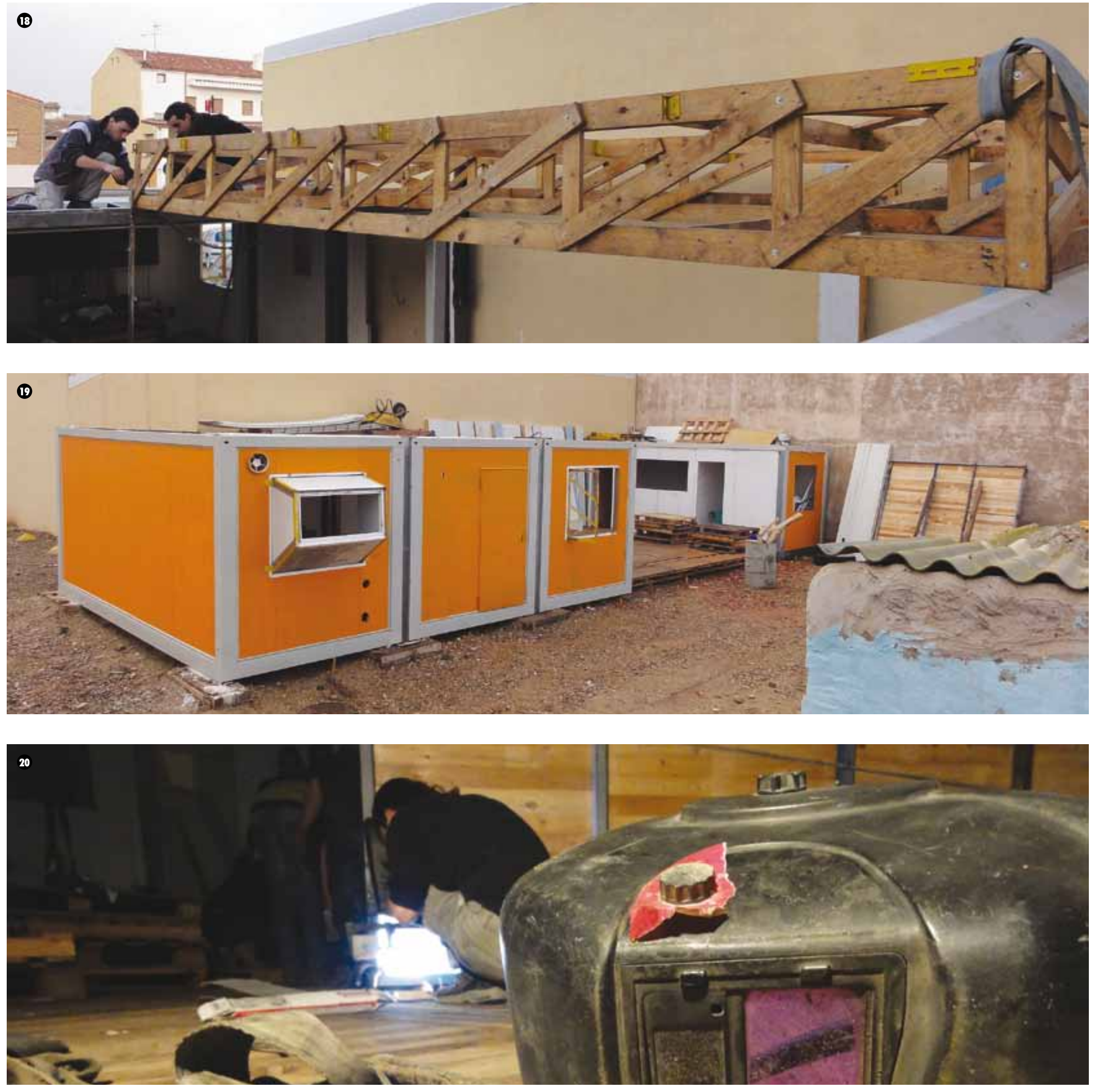
21, 22 y 23. Proyecto Barranco, Colectivo Los Avatares asociado con varios colectivos, Pradejón, España, 2011.
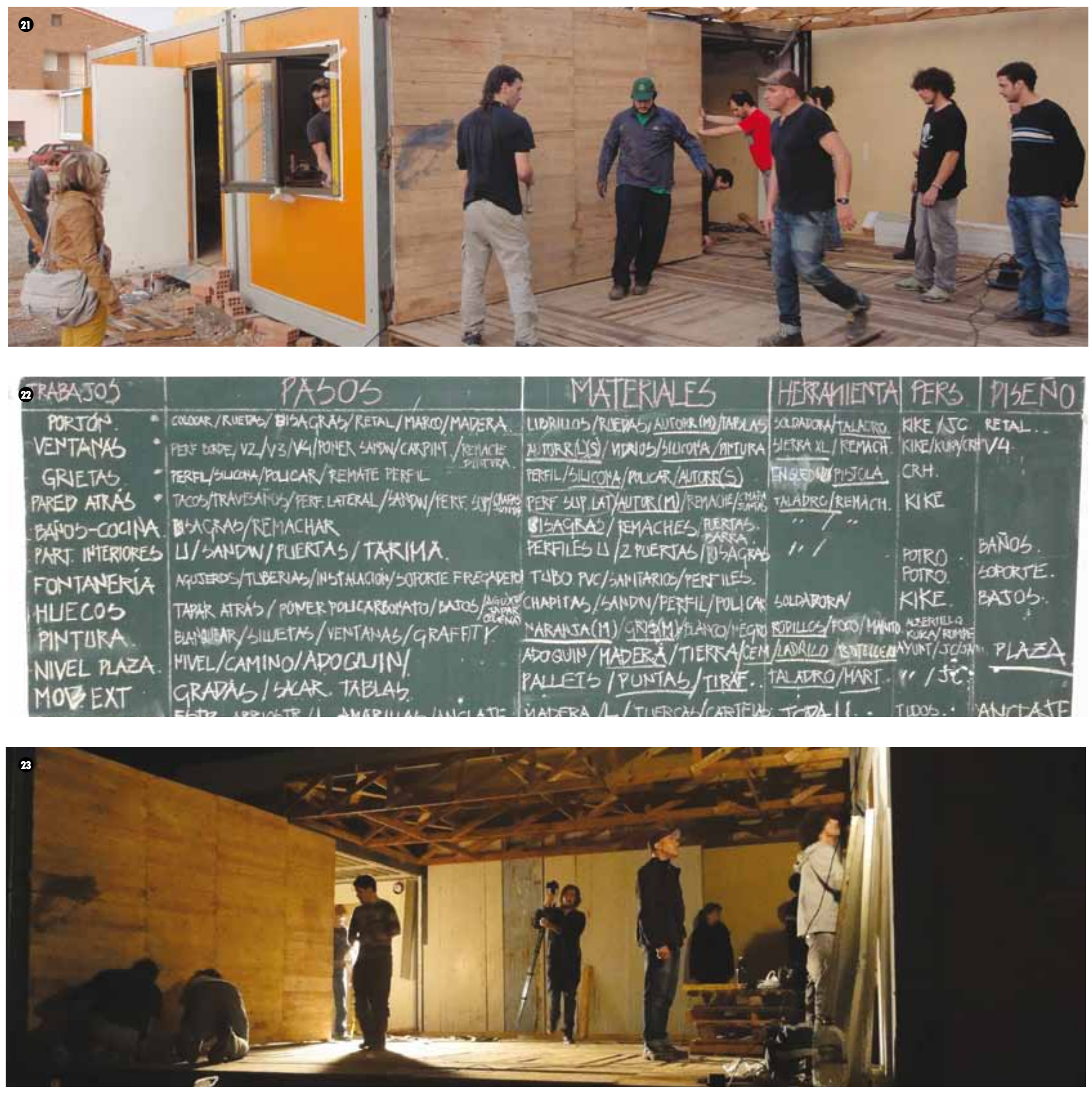


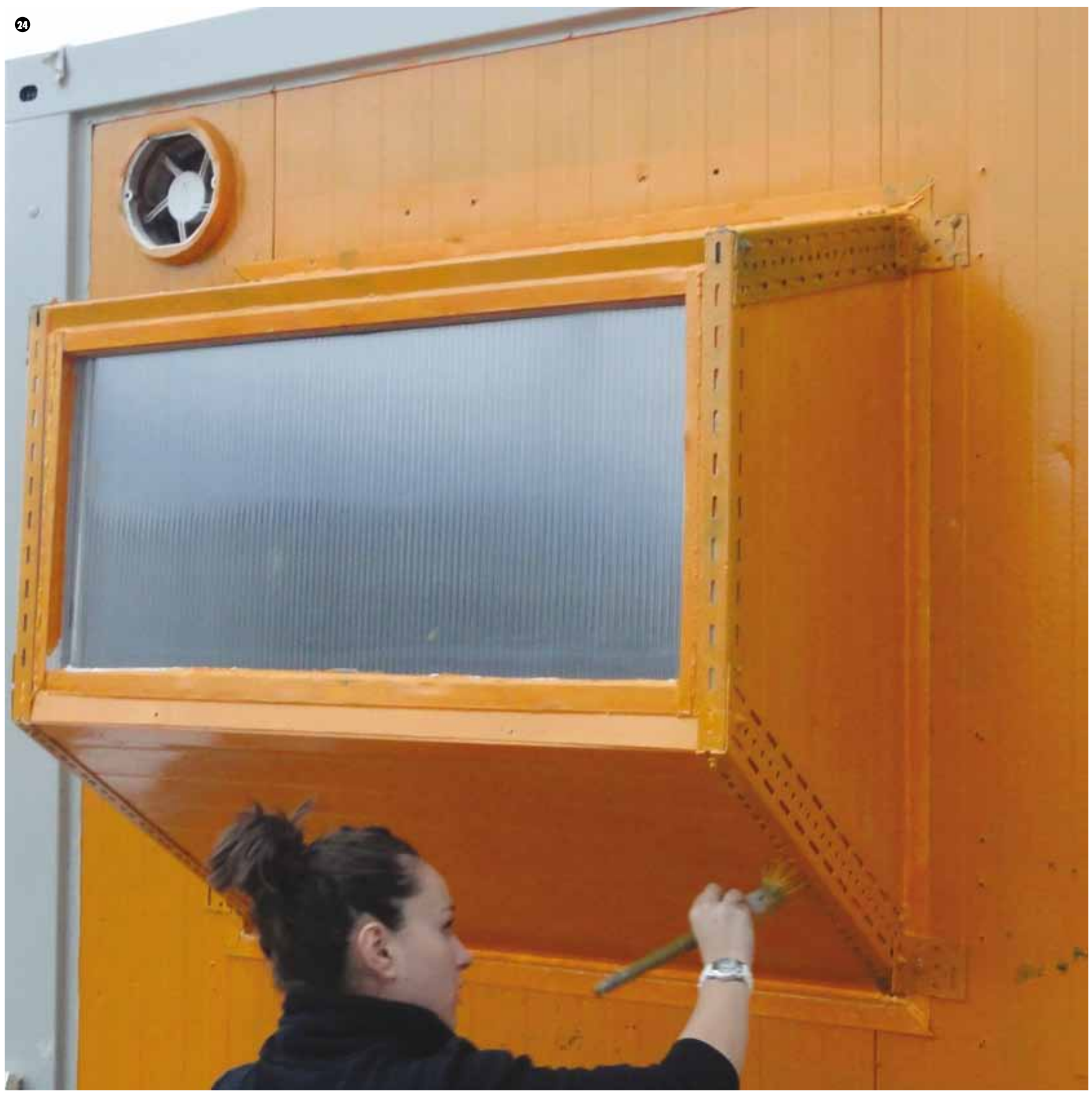


24 y 25. Proyecto Barranco, Colectivo Los Avatares asociado con varios colectivos, Pradejón, España, 2011.

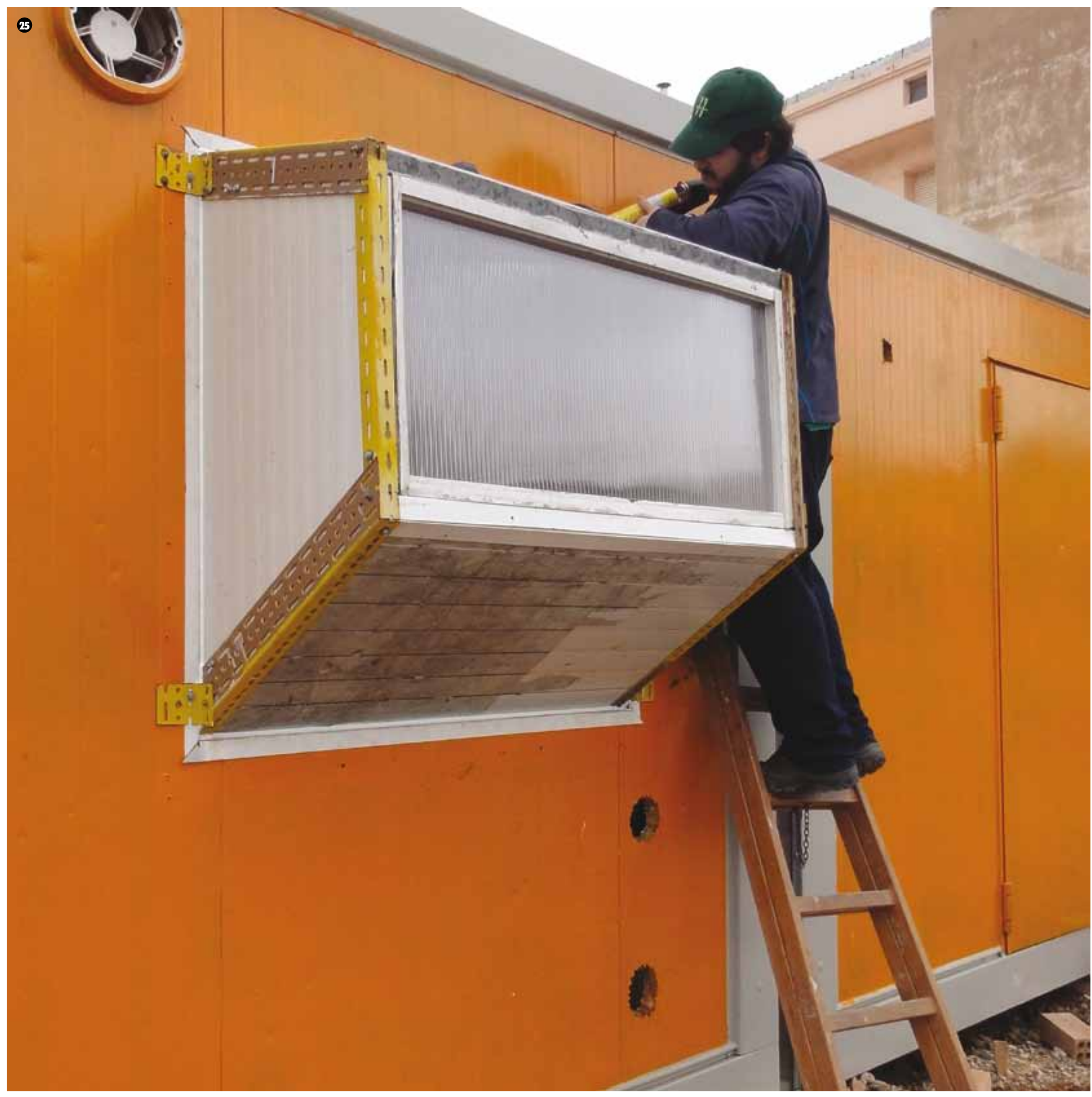

